\title{
What works in drug addiction?
}

\author{
Jason Luty
}

Abstract Treatment of illicit drug dependence typically involves a combination of pharmacotherapy and psychosocial interventions. Efficacy research supports methadone maintenance in opiate dependence. There is less evidence to support buprenorphine (an opiate receptor partial agonist), lofexidine (an $\alpha_{2}{ }^{-}$ adrenoreceptor agonist) and naltrexone (an opiate receptor antagonist). Evidence for the effectiveness of detoxification, which one of the most widely used treatments, is poor. Of the psychosocial interventions, reasonable evidence exists for the effectiveness of motivational interviewing. Other psychosocial treatments have rarely been compared with no or minimal contact conditions in randomised trials, and their reported effectiveness is often weak. Residential treatments are not demonstrably more effective than community programmes.

Substance dependence, or 'addiction', is diagnosed taking several factors into consideration (Box 1). Substance misuse refers to the non-therapeutic use of drugs in a manner that is potentially harmful, but does not meet criteria for dependence. Guidelines for drug addiction treatment have been published by the Department of Health (1999).

Many trials report significant benefits of addiction treatments (National Consensus Development Panel, 1998). However, only $20 \%$ of subjects report abstinence from all illicit substances for at least 1 year, despite receiving treatment. Furthermore, drop-out rates of nearly $50 \%$ are common. It is notable that only half of patients with other chronic disorders (such as hypertension or diabetes) fully adhere to medication schedules, and high drop-out rates are common in many forms of psychotherapy.

Trials of treatment for drug addiction are liable to all the common methodological flaws seen in clinical trials in psychiatry, including failure to use intention-to-treat analysis, failure to randomise results, lack of socio-demographically matched control groups and confounding due to unplanned variations in contact with treatment services. A US government report recently concluded that 'results derived from self-selected patients who remain in treatment optimistically skew findings in favour of effectiveness' (National Research Council, 2002).

There is no consensus on outcome measures of trials of addiction treatments. Urine (and saliva) analysis can provide objective measures of drug use. However, many trials report subjective ratings, such as scores on the Addiction Severity Index (McLellan et al, 1980), a 45-minute semi-structured interview

\section{Box 1 Diagnostic features for substance dependence}

Three or more of the following should have been present in the previous year:

- a compulsion to take the substance

- escalation of amount used

- a withdrawal syndrome following reduction in use

- tolerance

- neglect of other activities in favour of substance use (salience)

- persistent use despite evidence of harm

based on psychosocial functioning and drug use. Meta-analysis results are often expressed as an effect size: the difference in mean scores divided by the pooled standard deviation. This statistical technique allows the direct comparison of the results of trials that have used different outcome measures. A trial comparing 50-100 users and controls is usually sufficient to identify a treatment with a modest effect size (conventionally $0.25-0.5$ ) that is likely to be clinically significant.

\section{Pharmacotherapy for drug dependence}

There are no effective medications for treating stimulant dependence, despite trials of several agents (Bruce, 2000; de Lima et al, 2002). Hence, most

Jason Luty is a specialist registrar in psychiatry (Marina House, Addictions Resource Centre, 63/65 Denmark Hill, Camberwell, London SE5 8RS, UK). He has published in the addictions field and is involved with the Maudsley Hospital Community Drug Team. 


$\begin{array}{lll}\text { Table } 1 \text { Drugs used in opioid dependence } \\ \begin{array}{l}\text { Medication } \\ \text { Methadone }\end{array} & \begin{array}{l}\text { Action } \\ \text { Opioid agonist }\end{array} & \begin{array}{l}\text { Typical daily dose } \\ \text { orally }\end{array} \\ \text { Buprenorphine } & \text { Partial agonist } & \begin{array}{l}8-24 \mathrm{mg} \\ \text { sublingually }\end{array} \\ \text { Naltrexone } & \text { Opioid agonist } & 50 \mathrm{mg} \text { orally } \\ \text { Lofexidine } & \begin{array}{l}\alpha_{2} \text {-adrenergic } \\ \text { agonist }\end{array} & \begin{array}{l}0.8-2.4 \mathrm{mg} \\ \text { orally }\end{array}\end{array}$

research involves treatment of opiate dependence. Commonly used agents are summarised in Table 1.

\section{Methadone maintenance}

Maintenance treatment involves the prolonged prescription of a drug with no intention to reduce the dose, whereas detoxification is any treatment intended to produce abstinence from drug use (including prescribed drugs).

Methadone is a long-acting opioid agonist that is used to prevent withdrawal symptoms in opioid addicts. Persistent use leads to cross-tolerance and reduces the reinforcement effects of illicit opiates. Ward et al (1999) have produced an excellent short review of methadone treatment.

An influential meeting of experts in the USA concluded that the safety and efficacy of methadone maintenance treatment 'has been unequivocally established' (National Consensus Development Panel, 1998). Many studies have shown the advantages of methadone maintenance in reducing drug use, criminality and blood-borne virus infection and improving general health and social status. The median death rate for addicted individuals maintained on methadone is $30 \%$ of that for those who are not in treatment. Urine analysis from one sample of 435 methadone maintenance clients showed that almost half were able to quit daily heroin after 12 months (Simpson et al, 1997). The average number of 'crime-days' fell from eleven per month to four. Two large cohort studies suggest that the odds of HIV infection were five times greater among those who were not in methadone maintenance treatment than among those who were (Ward et al, 1999).

A classic double-blind study involved 100 heroin addicts in Hong Kong who were randomised to methadone maintenance or methadone detoxification at $1 \mathrm{mg}$ /day (Newman \& Whitehill, 1979). Retention rates were $60 \%$ in the maintenance group and $5 \%$ in the detoxification group. Urine analysis at 2-year follow-up indicated that $70 \%$ of subjects in the maintenance group had abstained from illicit opiate use in the previous month.
Methadone doses above $60 \mathrm{mg}$ per day are often required to prevent heroin use. However, it is important to note that initial methadone doses should be less than $40 \mathrm{mg}$ per day to prevent accidental overdose in individuals who have not developed a high tolerance to opiates. One study concluded that patients who receive doses of less than $60 \mathrm{mg}$ of methadone have nearly five times the risk of dropping out as those who receive doses of $80 \mathrm{mg}$ or more (Capelhorn \& Bell, 1991). A doubleblind trial of 193 intravenous opiate addicts revealed that $53 \%$ of the urine samples after 30 weeks were heroin-positive in those randomised to $80-100 \mathrm{mg}$ methadone, compared with $62 \%$ of those on 40-50 mg (Strain et al, 1999).

\section{Contingency management in methadone maintenance and cocaine treatment}

Contingency management techniques make clinic privileges or even continued prescribing available pending objective evidence of abstinence from illicit drugs.

McCarthy \& Borders (1985) reported a controlled trial of 69 patients on methadone maintenance programmes who were randomised so that for half the patients, prescribing would be discontinued after 4 consecutive months with one or more opioidpositive urine result. Intention-to-treat analysis indicated that $48 \%$ of patients in the trial sample were drug-free at one year compared with $31 \%$ in the more liberal control group. Unfortunately, aversive control techniques (such as reduction of methadone) lead to some patients leaving treatment. Positive control techniques are reported by Stitzer et al (1992) in a study of 53 patients in methadone maintenance who were randomly assigned to contingent or non-contingent take-home privileges: up to three take-home doses per week were permitted following 2 consecutive weeks of drug-free urine samples. The contingent group produced more individuals with at least 4 consecutive weeks of abstinence $(32 \% v .8 \%)$ over the 6 -month trial.

Comparable results are reported in a randomised controlled trial of opiate and cocaine addicts in which clean urine samples were rewarded with vouchers that could be exchanged for retail goods (Higgins et al, 1994; Preston et al, 2000).

\section{Opioid detoxification}

Medical detoxification relies on the use of agents, including methadone, buprenorphine, lofexidine or clonidine, in relatively short courses to suppress withdrawal symptoms. The daily dose of methadone can comfortably be reduced at rates of $1 \mathrm{mg}$ per week 
in the community or $5 \mathrm{mg}$ per day as an in-patient. Detoxification is widely used, and it is perhaps surprising to find that it is one of the least effective treatments for drug addiction.

A major problem with opioid detoxification is the rate of relapse. A US follow-up study of 10000 opiate addicts (the Drug Abuse Reporting Program; Simpson \& Friend, 1988) found that patients entering out-patient detoxification had almost half the abstinence rate at discharge when compared with other treatment modalities (12\% v. 18-21\%). The results for Newman \& Whitehill's (1979) randomised controlled trial of methadone maintenance indicated that detoxification had poor outcomes. The expert National Consensus Development Panel (1998) concluded that 'although the drug-free state represents an optimal treatment goal, research has demonstrated that the state cannot be achieved or sustained by the majority of persons dependent on opiates'.

\section{Other agents used in the treatment of opioid dependence}

Clonidine and lofexidine are $\alpha_{2}$-adrenoreceptor agonists that reduce somatic symptoms of opioid withdrawal. Opioid detoxification with these agents can be achieved in 5-7 days. However, neither agent can suppress symptoms such as craving, lethargy, insomnia, restlessness and muscle aches. Adverse effects include sedation and hypotension, although these are less common with lofexidine.

A systematic Cochrane review of 10 studies comparing $\alpha_{2}$-agonists and methadone detoxification over 10 days found no difference in efficacy, although more clients remained in contact with treatment services following methadone detoxification (Gowing et al, 2002). Kleber et al (1985) reported a trial of 49 methadone maintenance patients randomised to out-patient detoxification with clonidine or reducing doses of methadone over 30 days. Forty per cent completed the detoxification process, of whom one-third were abstinent at 6-month follow-up. An equivalent proportion had returned to methadone maintenance. There was no significant difference in outcome between the groups.

Buprenorphine is a partial opioid agonist and partial antagonist that is given sublingually. It might have a lower risk of overdose than methadone and produce less severe dependence, allowing a smoother withdrawal than methadone. A metaanalysis identified five randomised clinical trials, involving 540 patients over 16-26 weeks. This showed that buprenorphine was comparable with methadone in preventing illicit drug use, although it was more expensive (Barnett et al, 2001). Around
$50 \%$ of urine tests were positive for illicit opiates. Doses of 8-12 mg per day of buprenorphine have been shown to be as effective as $60-90 \mathrm{mg}$ of methadone (Schottenfeld et al, 1997). The risk that oral buprenorphine will be injected is greater than that for oral methadone and to deter this, a combination of buprenorphine with naloxone is being developed (the naloxone nullifies the buprenorphine only when injected).

Naltrexone is an opioid antagonist that produces no psychoactive effects or dependence. Naltrexone completely blocks the effects of opiates and acts as an 'insurance policy' against opiate use. It can precipitate acute withdrawal and should only be used following abstinence from all opioids (including methadone). Treatment can be given daily or three times per week. Unfortunately, naltrexone has not proven effective in treatment settings (Kirchmayer et al, 2002), although peculiarly, some investigators appear to have viewed it as a direct alternative to methadone rather than as an approach that can enable a completely opiate-free state. For example, in one trial only 15 of 300 patients chose naltrexone instead of detoxification or methadone maintenance, and of those 15 , only three continued naltrexone for more than 2 months (Fram et al, 1989).

L-alpha-acetylmethadol (LAAM) is a long-acting opiate agonist like methadone. It is not available in the UK, following reports of cardiotoxicity.

\section{Ultra-rapid opiate detoxification}

Ultra-rapid opiate detoxification involves administration of opiate antagonists (naloxone and naltrexone) to opiate-addicted individuals under general anaesthesia. This leads to an acute withdrawal. No large-scale controlled trials of this procedure have been published $\left(\mathrm{O}^{\prime}\right.$ Connor \& Kosten, 1998). Concerns about safety, expense and effectiveness also limit its usefulness. Ultra-rapid opiate detoxification was recently the subject of a General Medical Council investigation following the death of a patient during recovery, resulting in the anaesthetist involved being struck off (Bedenoch, 2002). It seems unlikely that there will be any enthusiasm for ultra-rapid opiate detoxification among clinicians in the foreseeable future, although less drastic measures involving sedation rather than anaesthesia are not so controversial.

\section{Injectable opioid treatment}

Heroin is available to addicts in the UK from licensed specialists. Parenteral methadone is also available, with licensing not required. Hartnoll et al (1980) reported a 12-month follow-up trial of intravenous heroin $v$. oral methadone on 96 heroin-addicted 
individuals in London. Those on heroin maintenance were twice as likely to remain in treatment ( $74 \%$ v. $29 \%$ ). However, the proportion remaining dependent on opiates (prescribed and illicit) at 12 months was higher in the heroin maintenance group $(90 \%$ v. $70 \%)$. There were no differences between the groups for self-reported criminal activity, health or employment. This report led to greatly reduced enthusiasm for injectable opioid treatment. Another UK trial found no advantage between injectable methadone and oral methadone (Strang et al, 2000).

Injectable opioid treatment is claimed by some enthusiasts to engage users in treatment more effectively than oral alternatives. Opponents suggest that it perpetuates injecting behaviour and thereby postpones eventual abstinence from heroin and also, in effect, endorses injecting. The treatment is expensive and there is a risk of deep-vein thrombosis and infection. The prospect of being offered injectable opiates may also provide some users with a vested interest in poor compliance with methadone maintenance. Relatively few patients are ever likely to receive the treatment, so the overall effects on crime will be small. Needle exchange programmes probably reduce health risks more than the prescription of injectables. The available evidence does not support the widespread adoption of injectable opioid treatment.

\section{Psychosocial treatment}

\section{Intensity of psychotherapy}

Many studies have shown that the intensity and duration of involvement in drug misuse treatment programmes is one of the best predictors of outcome (National Consensus Development Panel, 1998). However, the 'more is better' idea is often based on uncontrolled follow-up studies, in which patient motivation and selection might be primarily responsible for the good outcome.

Kraft et al (1997) reported a trial of 100 opiateaddicted patients, randomised to three psychosocial treatments of 6 months duration: minimum-contact methadone maintenance; methadone maintenance plus standard drug counselling three times weekly; and an enhanced programme of psychosocial treatment with daily counselling, family therapy and social work activity to enhance job prospects, housing and address other social problems. However, many of the subjects who were randomised to the enhanced programme actually attended only once each week, despite the offer of more-frequent sessions. All patients received $60-90 \mathrm{mg}$ methadone per day. Abstinence from opiates and cocaine use at 1 year were $29 \%, 47 \%$ and $49 \%$ of clients in the minimum-contact, standard and enhanced groups, respectively. These results were less promising than a partially randomised earlier trial. Overall, the enhanced programme did not confer significant benefit over standard drug counselling, although it was better than minimum-contact methadone maintenance. A cost-effectiveness analysis confirmed this.

\section{Narcotics Anonymous \\ and its 12-step approach}

Narcotics Anonymous provides support groups for problem drug users. These groups are widely available and are free to participants. Applying the disease model to substance misuse, they promote the 12-step approach. This involves recognition that addiction is a relapsing illness that requires complete abstinence (Box 2). Participants are

\section{Box 2 The 12 steps of Narcotics Anonymous}

1 We admitted that we were powerless over our addiction, that our lives had become unmanageable.

2 We came to believe that a Power greater than ourselves could restore us to sanity.

3 We made a decision to turn our will and our lives over to the care of God as we understood Him.

4 We made a searching and fearless moral inventory of ourselves.

5 We admitted to God, to ourselves, and to another human being the exact nature of our wrongs.

6 We were entirely ready to have God remove all these defects of character.

7 We humbly asked Him to remove our shortcomings.

8 We made a list of all persons we had harmed and became willing to make amends to them all.

9 We made direct amends to such people wherever possible, except when to do so would injure them or others.

10 We continued to take personal inventory and when we were wrong we promptly admitted it.

11 We sought through prayer and meditation to improve our conscious contact with God as we understood Him, praying only for knowledge of His will for us and the power to carry that out.

12 Having had a spiritual awakening as a result of these steps, we tried to carry this message to addicts and to practice these principles in all our affairs. 
required to acknowledge their addiction and the harm they are causing themselves and others. No randomised controlled trials have attempted to determine the effectiveness of Narcotics Anonymous or of 12-step approaches in opiate addiction. However, a study of 487 cocaine users, all of whom received group drug counselling throughout the trial, involved randomisation to individual counselling (based on the 12-step approach), supportiveexpressive psychotherapy or cognitive-behavioural therapy (CBT) with a 1-year follow-up (CritsChristoph et al, 1999). One-third of the eligible cocaine users were recruited, of whom $28 \%$ completed the 6-month treatment programmes. Cocaine use was reduced from a mean of 10 days per month to only 3 days. However, $71 \%$ of the group receiving a combination of individual and group 12-step counselling were abstinent for at least 1 month, compared with 55-60\% for combinations of group counselling with formal psychotherapy. The psychotherapy approaches were able to retain more clients in treatment (33\% completed treatment $v .22 \%$ for drug counselling). Similarly, Wells et al (1994) report a controlled comparison of CBT-based relapse prevention $v$. 12-step approaches in out-patient treatment of 110 cocaine users. The two treatments were equally effective at 1 year, and the number of days of cocaine use halved. Overall, the evidence suggests that the 12-step approach is at least as effective as other structured psychotherapies.

\section{Relapse prevention and cognitive-behavioural therapy}

Relapse prevention techni ques using CBT are based on the work of Marlatt \& Gordon (1985). The techniques assume that substance misuse is a means of coping with difficult situations, dysphoric mood and peer pressure. Treatment aims to help patients recognise high-risk situations and either avoid or cope with them without drug use.

Irvin et al (1999) reported a meta-analysis of five randomised controlled trials of relapse prevention treatment for polydrug misuse. The overall effect was modest. For example, Carroll et al (1994) compared CBT-based treatment with routine clinical management over 1 year for cocaine addicts. CBT was only superior for those who were also depressed and for those with high levels of cocaine use. Wells et al (1994) found no difference between CBT-based relapse prevention and a 12-step approach in cocaine users (see above).

In one randomised controlled trial with 64 amphetamine-using patients, 2-4 CBT/motivational interviewing sessions were compared with provision of a self-help booklet. Clients typically attended half the sessions. The number of clients who abstained from amphetamine use in the treatment group compared with the self-help group increased from $21 \%$ to $38 \%$ (Baker et al, 2001).

Overall, CBT approaches are better researched, but probably no more effective than the other psychological methods in addiction.

\section{Psychodynamic psychotherapy}

There is a widespread opinion that psychodynamic psychotherapy is of low acceptability to drug misusers, as illustrated by a trial of interpersonal psychodynamic psychotherapy with 72 opiate addicts in methadone maintenance (Rounsaville et al, 1983). Weekly individual interpersonal therapy was compared with monthly 'low-contact' control treatment. Both treatments continued for 6 months. Only $5 \%$ of eligible clients agreed to attend psychotherapy and only $38 \%$ of these completed the interpersonal therapy programme. There were no significant differences in outcome between the two groups, although both made significant gains. Woody et al (1995) reported a similar randomised trial of supportive-expressive psychotherapy, in which the overall effect size was small (0.26). Other investigators have failed to find advantages for psychodynamic psychotherapy in substance misuse (Crits-Christoph et al, 1999).

\section{Motivational interviewing/motivational enhancement therapy}

Motivational interviewing is a technique described by Miller \& Rollnick (2002). It is based on theories of cognitive dissonance and attempts to promote a favourable attitude change. Briefly, instructing addicts of the problems of dependency and the advantages of abstinence tends to provoke contradictory arguments from the client. This might reinforce continued dependence. Motivational interviewing encourages clients to give their own reasons for attempting to change their drug use.

A systematic review identified five randomised trials of motivational interviewing in drug dependence, involving 800 patients (Dunn et al, 2001). Typical effect sizes were 0.5-0.6 (although confidence intervals were large). One randomised trial of 122 opiate addicts found that motivational interviewing compared with health education alone increased retention in methadone programmes at 6 months from $50 \%$ to $70 \%$ (Saunders et al, 1995). Booth et al (1998) reported a trial of 4000 intravenous drug users seeking HIV testing. Subjects were randomly assigned to either standard testing alone or testing plus three sessions of motivational counselling from a health educator. At 6-month 
follow-up, the latter group showed half the rate of drug injection ( $20 \%$ v. $45 \%$ ) and were four times more likely to be abstinent (confirmed by urine analysis). They also had significantly lower arrest rates $(14 \%$ v. $24 \%)$.

\section{Community reinforcement, couple and family therapies}

Reinforcement treatments typically involve clients' partners or families rewarding them for abstinence using agreed strategies. Stanton \& Shadish (1997) performed a meta-analysis of 15 randomised controlled trials, involving 1571 opiate addicts, that compared couple/family therapy with individual counselling, peer-group therapy and family psychoeducation. Six of the trials involved adult clients. Family therapy methods had an effect size of 0.46 greater than non-family therapy at 1 year. The dropout rate was also lower in the family therapy group ( $45 \%$ compared with $\sim 25 \%)$.

Community reinforcement using families and couples are feasible and show some effectiveness, although they are often overlooked. Not all clients have family members or partners who are willing to be involved in substance misuse treatment. However, where they can be recruited as co-therapists, family members can be encouraged to provide agreed rewards to clients for abstinence. The nature of the reward needs to be negotiated in advance with the client and family member. Family members also provide a degree of surveillance over the clients and can provide supervision, support, advice or comment if clients begin using drugs again, feel tempted or put themselves in risk situations.

\section{Therapeutic communities and residential rehabilitation units}

These units typically require prolonged residence (often 12-18 months). Clients are closely involved in running the programmes, including selecting and discharging residents. Abstinence is usually a prerequisite. Several large studies suggest that therapeutic communities are beneficial, although completion rates for prolonged residential programmes are often below $20 \%$.

A trial of 585 male heroin addicts involved random assignment to methadone maintenance or therapeutic communities (Bale et al, 1980). The outcomes between the two groups were comparable. Roughly half of the subjects who completed the programmes reported heroin use during the 12th (and final) month of the study. Unfortunately, only $18 \%$ of the subjects randomised to the therapeutic communities actually began the 6-month residential programmes.
Overall, only $10 \%$ of subjects successfully engaged in either of the programmes to which they had been assigned.

The National Treatment Outcome Research study is a follow-up of 1075 clients (most of whom were addicted to heroin) attending UK drug treatment agencies (Gossop et al, 2003). At 5 years, $42 \%$ of those who were attending community methadone programmes at the start of the study were regularly using heroin, compared with $39 \%$ of those who were in residential programmes at intake (and were subsequently discharged). Although the study was not randomised, these results support North American research demonstrating that residential programmes are no more effective than community programmes, despite the greatly increased cost.

\section{Other approaches}

A government report recently concluded that 'because of lack of investment in data and research, the nation is in no better position to evaluate the effectiveness of enforcement than it was 20 years ago' (National Research Council, 2002).

Drug treatment and testing orders were introduced in the UK under the Crime and Disorder Act 1998. Orders last from 6 months to 3 years. Under the relevant legislation, courts can require an offender to undergo treatment for drug misuse, subject to the offender's consent to such an order being made. Offenders are required to undergo testing for use of illicit substances and to 'submit' to treatment. If treatment is not satisfactory or clients reoffend, the court may sentence them again. Turnbull et al (2000) report the results of the pilot programmes, involving 210 offenders. The percentage of opioid-positive urine tests (excluding methodone) fell from $42 \%$ to $13 \%$. However, approximately half of the offenders were discharged from the orders for breach of terms. These results are disappointing, despite US reviews suggesting that coerced offenders do no worse than voluntary clients (Anglin \& Hser, 1991).

Needle exchanges have been widely adopted, their main purpose being to prevent transmission of HIV and hepatitis. Most surveys have concluded that they are effective in reducing needle sharing and blood-borne viruses and they encourage drug users to seek help. Needle exchange programmes do not appear to have caused an increase in injecting (Royal College of Psychiatrists, 2000). An Australian study concluded that the cost-effectiveness of needle exchanges varied from Aus $\$ 50$ to Aus $\$ 7000$ per lifeyear saved. There are no randomised controlled trials of needle exchange schemes or drug treatment and testing orders. 


\section{Conclusions}

What works in drug addiction? Methadone maintenance has been shown to be safe and very effective on a variety of measures, including preventing illicit drug use. Buprenorphine is probably equally effective, although it is more expensive in some countries. Reasonable evidence exists for the effectiveness of motivational interviewing. Few randomised controlled trials compare other psychosocial treatments with no or minimal contact conditions. However, where evidence does exist, the effect size is often modest. Evidence for the effectiveness of detoxification is poor, even though this is one of the most widely used treatments. Residential treatments are not demonstrably more effective than community programmes.

\section{References}

Anglin, M. D. \& Hser, Y. I. (1991) Criminal justice and the drug-abusing offender: policy issues of coerced treatment. Behavioural Sciences and the Law, 9, 243-267.

Baker, A., Boggs, T. G. \& Lewin, T. J. (2001) Randomised controlled trial of brief cognitive-behavioural interventions among regular users of amphetamine. Addiction, 96, 12791287.

Bale, R. N., Stone, W. W. V., Kuldau, J. M., et al (1980) Therapeutic communities vs methadone maintenance. Archives of General Psychiatry, 37, 179-193.

Barnett, P. G., Rodgers, J. H. \& Bloch, D. A. (2001) A metaanalysis comparing buprenorphine to methadone for treatment of opiate dependence. Addiction, 96, 683-690.

Bedenoch, J. (2002) A death following ultra-rapid opiate detoxification. Addiction, 97, 475-477.

Booth, R. E., Kwiatkowski, C., Iguchi, M. Y., et al (1998) Facilitating treatment entry among out-of-treatment injection drug users. Public Health Report, 113 (suppl. 1), s116-s128.

Bruce, M. (2000) Managing amphetamine dependence. Advances in Psychiatric Treatment, 6, 33-40.

Capelhorn, J. R. \& Bell, J. (1991) Methadone dosage and retention of patients in maintenance treatment. Medical Journal of Australia, 154, 195-199.

Carroll, K. M., Rounsaville, B. J. \& Gordon, L. T. (1994) Psychotherapy and pharmacotherapy for ambulatory cocaine abusers. Archives of General Psychiatry, 51, 989-997.

Crits-Christoph, P., Siquel, L., Blaine, J., et al (1999) Psychosocial treatments for cocaine dependence. Archives of General Psychiatry, 56, 493-502.

de Lima, M. S., de Oliveria Soares, B. G., Reisser, A. A., et al (2002) Pharmacological treatment of cocaine dependence: a systematic review. Addiction, 97, 931-949.

Department of Health (1999) Drug Misuse and Dependence Guidelines on Clinical Management. London: Stationery Office.

Dunn, C., Deroo, L. \& Rivara, F. P. (2001) The use of brief interventions adapted from motivational interviewing across behavioural domains: a systematic review. Addiction, 96, 1725-1742.

Fram, D. M., Marmo, J. \& Holden, R. (1989) Naltrexone treatment - the problem of patient acceptance. Journal of Substance Abuse Treatment, 6, 119-122.

Gossop, M., Marsden, J., Stewart, D., et al (2003) The national treatment outcome research study: 4-5 year follow-up results. Addiction, 98, 291-303.

Gowing, L. R., Farrell, M., Ali, R. L., et al (2002) Alpha-2adrenergic agonists in opioid withdrawal. Addiction, 97, $49-58$.
Hartnoll, R. L., Mitcheson, M. C., Battersby, A., et al (1980) Evaluation of heroin maintenance in controlled trial. Archives of General Psychiatry, 37, 877-884.

Higgins, S. T., Budney, A. J. \& Bickel, W. K. (1994) Incentives improve outcome in outpatient behavioural treatment of cocaine dependence. Archives of General Psychiatry, 51, 568576.

Irvin, J. E., Bowers, C. A., Dunn, M. E., et al (1999) Efficacy of relapse prevention: a meta-analytic review. Journal of Consulting and Clinical Psychology, 67, 563-570.

Kirchmayer, U., Davloi, M., Vester, A. D., et al (2002) A systematic review of the efficacy of naltrexone maintenance treatment in opioid dependence. Addiction, 97, 1241-1249.

Kleber, H. D., Riordan, C. E., Rounsaville, B., et al (1985) Clonidine in out-patient detoxification from methadone maintenance. Archives of General Psychiatry, 42, 391-394.

Kraft, M. K., Rothbard, A. B. \& Hadley, T. R. (1997) Are supplemental services provided during methadone maintenance really cost-effective? American Journal of Psychiatry, 154, 1214-1219.

Marlatt, G. A., \& Gordon, J. R. (1985) Relapse Prevention. New York: Guilford Press.

McCarthy, J. J. \& Borders, O. T. (1985) Limit setting on drug abuse in methadone maintenance patients. American Journal of Psychiatry, 142, 1419-1423.

McLellan, A. I., Luborsky, L., Woody, G. E., et al (1980) An improved diagnostic instrument for substance abuse patients: the Addiction Severity Index. Journal of Nervous and Mental Diseases, 168, 26-33.

Miller, W. R. \& Rollnick, S. (2002) Motivational Interviewing: Preparing People to Change Addictive Behaviour. New York: Guilford Press.

National Consensus Development Panel (1998) Effective medical treatment of opiate addiction. Journal of the American Medical Association, 280, 1936-1943.

National Research Council (2002) Executive summary of the National Research Council's report 'Informing America's policy on illegal drugs: what we don't know keeps hurting us'. Addiction, 97, 647-652.

Newman, R. G. \& Whitehill, W. B. (1979) Double-blind comparison of methadone and placebo maintenance treatment of narcotic addicts in Hong Kong. Lancet, 2, 484-488.

O'Connor, P. G. \& Kosten, T. R. (1998) Rapid and ultrarapid opioid detoxification techniques. Journal of the American Medical Association, 279, 229-234.

Preston, K. L., Umbricht, A. \& Epstein, D. H. (2000) Methadone dose increase and abstinence reinforcement for treatment of continued heroin use during methadone maintenance. Archives of General Psychiatry, 57, 395-404.

Rounsaville, B. J., Glazer, W., Wilber, C. H., et al (1983) Shortterm interpersonal psychotherapy in methadonemaintained opiate addicts. Archives of General Psychiatry, 40, 629-636.

Royal College of Psychiatrists (2000) Drugs: Dilemmas and Choices, p. 161. London: Gaskell.

Saunders, B., Wilkinson, C. \& Phillips, M. (1995) The impact of a brief motivational intervention with opiate users attending a methadone programme. Addiction, 90, 415424.

Schottenfeld, R. S., Pakes, J. R. \& Oliveto, A. (1997) Buprenorphine versus methadone maintenance treatment for concurrent opioid dependence and cocaine abuse. Archives of General Psychiatry, 54, 713-720.

Simpson, D. D. \& Friend, J. (1988) Legal status and longterm outcomes from addicts in the DARP follow-up project. In Compulsory Treatment of Drug Abuse (eds C. G. Leukefield \& F. M. Tims), pp. 81-98 (National Institute of Drug Abuse Research Monographs, no. 86). Rockville, MD: US Department of Health and Human Services.

-, Joe, G. W. \& Rowan-Szal, G. A. (1997) Drug abuse treatment retention and process effects on follow-up outcomes. Drug and Alcohol Dependence, 47, 227-235.

Stanton, M. D. \& Shadish, W. R. (1997) Outcome, attrition and family-couples treatment for drug abuse: a metaanalysis and review of controlled, comparative studies. Psychological Bulletin, 122, 170-191. 
Stitzer, M. L., Iguchi, M. Y. \& Flech, L. J. (1992) Contingent take-home incentive: effects on drug use on methadone maintenance patients. Journal of Consulting and Clinical Psychology, 60, 927-934.

Strain, E. C., Bigelow, G. E., Liebson, I. A., et al (1999) Moderate- Vs high-dose methadone: a randomised trial. Journal of the American Medical Association, 281, 1000-1005.

Strang, J., Marsden, M., Cummins, M., et al (2000) Randomised trial of supervised injectable versus oral methadone maintenance. Addiction, 95, 1631-1645.

Turnbull, P. J., McSweeney, T., Webster, R., et al (2000) Drug Treatment and Testing Orders: Final Evaluation Report (Home Office Research Study 212). London: Home Office.

Ward, J., Hall, W. \& Mattick, R. P. (1999) Role of maintenance treatment in opioid dependence. Lancet, 353, 221-226.

Wells, E. A., Peterson, P. L. \& Gainey, R. R. (1994) Outpatient treatment for cocaine abuse: a controlled comparison of relapse prevention and twelve-step approaches. American Journal of Drug and Alcohol Abuse, 20, 1-17.

Woody, G. E., McLellan, A. T., Luborsky, L., et al (1995) Psychotherapy in community methadone programs. American Journal of Psychiatry, 152, 1302-1308.

\section{Multiple choice questions}

1 The following are diagnostic features for substance dependence:

a compulsion

b withdrawal syndrome

c salience

d satiety

e tolerance.

2 Methadone maintenance:

a is less effective than detoxification

b should always be discontinued following continued illicit drug use

c should not usually be started at doses above $40 \mathrm{mg}$

$\mathrm{d}$ has been shown to be effective in randomised controlled trials

e is optimally effective with daily doses of $30 \mathrm{mg}$ or below.
3 Drugs commonly recommended to treat opiate addiction include:

naltrexone

b chlorpromazine

c diamorphine

d lofexidine

e chlordiazepoxide.

4 The 12-step approach to treat addiction:

a has been shown to be less effective than CBT-based methods

b has a strong spiritual element

c is universally effective for cocaine addicts

d can be combined with motivational enhancement

e remains the only effective relapse prevention strategy.

5 Most research has shown the following addiction treatments to be effective:

a methadone maintenance

b family therapy

c needle exchange programmes

d therapeutic communities

e motivational interviewing.

\section{INVITED COMMENTARY ON What works in drug addiction?}

Few psychiatric specialities attract so much attention from other authorities and the general public as drug misuse. It is one of the major social problems of our time, and causes great difficulties for those who have become addicted, those around them and the community at large-not least through the effects of drug-related crime. Whether treatment is effective is not a matter simply of academic interest, but one that must be critically and correctly analysed so that the balance that society has to strike between enforcement, preventive measures and treatment can be fairly judged. There can be a tendency for clinicians to overstate the effectiveness of treatment, perhaps partly because of a humane concern that incarceration, for instance, might make matters worse for their patients. However, this temptation must surely be resisted, as the realities of ongoing drug use, even in the face of advice, are often all too 